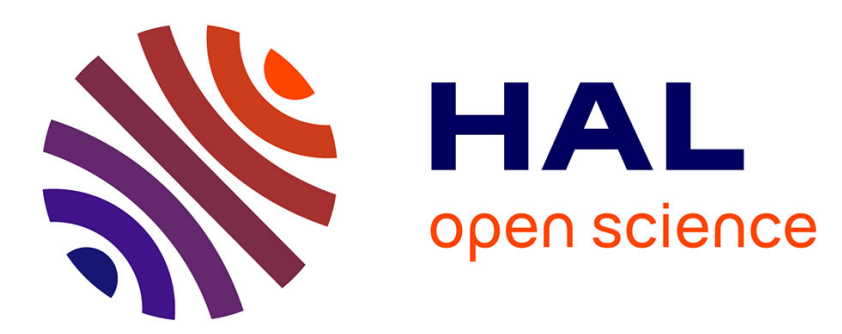

\title{
A comparison of the migration entropy for the cation and the anion vacancy motion in alkali halides with $\mathrm{NaCl}$ and $\mathrm{CsCl}$ type structure
}

\author{
P. Varotsos
}

\section{- To cite this version:}

P. Varotsos. A comparison of the migration entropy for the cation and the anion vacancy motion in alkali halides with $\mathrm{NaCl}$ and $\mathrm{CsCl}$ type structure. Journal de Physique Lettres, 1977, 38 (7), pp.171-172. 10.1051/jphyslet:01977003807017100 . jpa-00231352

HAL Id: jpa-00231352

https://hal.science/jpa-00231352

Submitted on 1 Jan 1977

HAL is a multi-disciplinary open access archive for the deposit and dissemination of scientific research documents, whether they are published or not. The documents may come from teaching and research institutions in France or abroad, or from public or private research centers.
L'archive ouverte pluridisciplinaire HAL, est destinée au dépôt et à la diffusion de documents scientifiques de niveau recherche, publiés ou non, émanant des établissements d'enseignement et de recherche français ou étrangers, des laboratoires publics ou privés. 


\title{
A COMPARISON OF THE MIGRATION ENTROPY FOR THE CATION AND THE ANION VACANCY MOTION IN ALKALI HALIDES WITH NaCl AND CsCl TYPE STRUCTURE
}

\author{
P. VAROTSOS \\ Department of Physics, University of Athens, Solonos Str. 104, Athens 144, Greece.
}

(Reçu le 7 février 1977, accepté le 9 mars 1977)

\begin{abstract}
Résumé. - Les entropies de migration de lacunes cationiques et anioniques dans les halogénures alcalins ont été calculées en fonction de paramètres macroscopiques (comme le module de compression et le coefficient de dilatation) et de l'enthalpie correspondante de migration au zéro absolu.

En conclusion, dans le cas d'une structure $\mathrm{NaCl}$, l'entropie de migration est plus grande pour le cation que pour l'anion. Dans le cas d'une structure $\mathrm{CsCl}$ l'inverse est valable.
\end{abstract}

\begin{abstract}
The entropy for the migration of a cation and an anion vacancy in alkali halides has been calculated through macroscopic parameters (such as bulk modulus and the volume expansion coefficient) and the corresponding enthalpy of motion at absolute zero.

It is concluded that in the case of a $\mathrm{NaCl}$ structure the cation migration entropy is greater than that for an anion vacancy motion. On the other hand in the case of a $\mathrm{CsCl}$ structure the opposite holds.
\end{abstract}

The entropy values $S_{m}^{+}$and $S_{m}^{-}$for cation and anion vacancy motion respectively in alkali halides are obtained experimentally from conductivity or diffusion experiments. As for their values, in recent years, a general agreement between various workers has been obtained due to the high accuracy (and the various precautions) of the recent measurements. Thus in a rough approximation we can say that in the case of an alkali halide with $\mathrm{NaCl}$ structure $S_{m}^{+}$lies between $1 k$ and $2 k$ whereas $S_{m}^{-}$has been found to be greater than $2 k$ i.e. $S_{m}^{-}=2 k-4 k$ (Table I). However we recall that both $S_{m}^{+}$and $S_{m}^{-}$values have been derived under the following assumption : [1, 2].

The pre-exponential frequency factor appearing

\section{TABLE I}

$\begin{array}{cccc} & S_{m}^{+} & S_{m}^{-} & \\ \text {Crystal } & \text { in } k \text { units } & \text { in } k \text { units } & \text { References } \\ - & - & - & - \\ \mathrm{NaCl} & 2-3 & 1.5-4.4 & {[1]} \\ & 1.75 & 2.2 & {[8]} \\ & 1.64 & 1.38 & {[7]} \\ \mathrm{KCl} & 1.8 & 4.2-6.3 & {[1]} \\ & 2.88 & 4.34 & {[8]} \\ \mathrm{KBr} & 2.40 & 3.20 & {[7]} \\ & 1.7 & 3.7 & {[1]} \\ & 2.54 & 3.95 & {[8]}\end{array}$

in the mobilities of both cation and anion vacancy is arbitrarily set equal to the Debye frequency $v_{D}$ of the host material. Although the selection of $v_{D}$ is arbitrary and may displace both $S_{m}^{+}$and $S_{m}^{-}$to higher or lower values, it is fairly sure [1] that the inequality $S_{m}^{+}<S_{m}^{-}$ will be unchanged.

The scope of this paper is to discuss on theoretical grounds the relation $S_{m}^{+}<S_{m}^{-}$(which is valid only in the case of a $\mathrm{NaCl}$ structure) and to find whether in some materials this inequality must be reversed. The present treatment is based on a recently proposed method [3] for the calculation of the free energy $g_{m}^{+}$ for a cation vacancy migration.

In an alkali halide crystal with $\mathrm{NaCl}$ structure $g_{m}^{+}$ can be expressed as follows [3] :

$$
g_{m}^{+}=\frac{A}{l}+c B \Omega
$$

where

(i) $l$ is the nearest cation-anion distance.

(ii) $\Omega$ is the volume per atom.

(iii) $A=\left(\alpha_{\mathbf{X}}-\alpha_{\mathrm{E}}\right) e^{2} / \varepsilon_{\infty}$ where $\alpha_{\mathrm{X}}, \alpha_{\mathrm{E}}$ are the Madelung constants of a normal lattice site $X$ and at the saddle point $E$ respectively and $\varepsilon_{\infty}$ the dielectric constant for high frequencies. Although $\varepsilon_{\infty}$ depends [4] on temperature, in the following we suppose that $A$ does not depend on temperature $T$. 
(iv) $c$ is a dilatation factor which is approximately equal to $1 / 8$ (The exact value of $c$ is not indispensable for the arguments of the present paper).

(v) $B$ is the local bulk modulus which is taken equal to the macroscopic bulk modulus.

$$
\begin{aligned}
& \text { Eq. (1) at } T=0 \text { gives : } \\
& \qquad h_{m, 0}^{+}=\frac{A}{l_{0}}+c B_{0} \Omega_{0}
\end{aligned}
$$

where $l_{0}, B_{0}, \Omega_{0}$ are the corresponding values at $T=0$ and $h_{m, 0}^{+}$is the migration enthalpy, also at absolute zero.

By substituting the value of $c$ obtained from eq. (2) into eq. (1) we get :

$$
g_{m}^{+}=\frac{A}{l}+\frac{\left(h_{m, 0}^{+} l_{0}-A\right) B \Omega}{l_{0} B_{0} \Omega_{0}} .
$$

Thus the migration entropy $S_{m}^{+}$is given by :

$$
\begin{aligned}
S_{m}^{+}=-\left(\frac{\mathrm{d} g_{m}^{+}}{\mathrm{d} T}\right)_{\mathrm{P}}=\frac{A \beta}{3 l_{0} b^{1 / 3}}- \\
-\frac{\left(h_{m, 0}^{+} l_{0}-A\right)}{l_{0} B_{0}} \times \frac{\mathrm{d}(B b)}{\mathrm{d} T}
\end{aligned}
$$

where

$$
b=\Omega / \Omega_{0}=\exp \int_{0}^{T} \beta \mathrm{d} T,
$$

$\beta$ is the volume expansion coefficient.

By combining eqs. (3) and (4) we find the migration enthalpy

$$
h_{m}^{+}=g_{m}^{+}+T s_{m}^{+}
$$

expressed by the macroscopic parameters $B$ and $\beta$ and the migration enthalpy $h_{m, 0}^{+}$at $T=0$.

It is clear that similar considerations hold for an anion vacancy motion; thus the entropy $S_{m}^{-}$for the migration of an anion is given by the following equation which is analogous to eq. (4) :

$$
S_{m}^{-}=\frac{A \beta}{3 l_{0} b^{1 / 3}}-\frac{\left(h_{m, 0}^{-} l_{0}-A\right)}{l_{0} B_{0}} \times \frac{\mathrm{d}(B b)}{\mathrm{d} T}
$$

Eqs. (4) and (5) give the migration entropies $S_{m}^{+}$, $S_{m}^{-}$through the macroscopic parameters $B$ and $\beta$ (which are experimentally well known) and the migrational enthalpies $h_{m, 0}^{+}$and $h_{m, 0}^{-}$.

In alkali halides with $\mathrm{NaCl}$ structure $h_{m, 0}^{+}<h_{m, 0}^{-}$ (since we know that the experimental migration enthalpy for an anion is greater than that for a cation, and setting $h_{m, \text { exper }} \simeq h_{m, 0}$ ).

By comparing eqs. (4) and (5) and keeping in mind [6] that $\mathrm{d}(B b) / \mathrm{d} T<0$ (for the temperature at which the usual conductivity and diffusion experiments have been made) we conclude that $S_{m}^{+}<S_{m}^{-}$as the experiments showed.

On the other hand in alkali halides with $\mathrm{CsCl}$ structure (and at temperatures in which they have not been transformed into $\mathrm{NaCl}$ type structure) we know that $h_{m, 0}^{+}>h_{m, 0}^{-}$; thus a similar comparison of eqs. (4) and (5) gives $S_{m}^{+}>S_{m}^{-}$.

The later result has not been well confirmed experimentally and experiments in this direction would be extremely interesting.

We add a last remark. In both eqs. (4) and (5) we have disregarded a term

$$
S_{\text {vibrational }}=k \sum_{i} \ln \frac{\omega_{i}^{(2)}}{\omega_{i}^{(1)}},
$$

where $\omega_{i}^{(2)}$ and $\omega_{i}^{(1)}$ are the frequencies of the neighbouring ions where the moving ion is at saddle point and its normal lattice site respectively. It seems probable that this term (which might have different values for a cation or an anion motion) is small as we have found [3] that the entropy values, given by differentiating eq. (3) (which must contain a term

$$
\left.-k T \sum_{i} \ln \frac{\omega_{i}^{(2)}}{\omega_{i}^{(1)}}\right)
$$

are in satisfactory agreement with experimental results. Thus the addition of such a term to eqs. (4) and (5) does not change the above considerations for the comparison of the entropies $S_{m}^{+}$and $S_{m}^{-}$.

\section{References}

[1] BARR, L. W. and Lidiard, A. B., in Physical Chemistry. An advanced Treatise (Academic Press) 1970, p. 177

[2] Varotsos, P., J. Physique Colloq. 37 (1976) C7 327.

[3] Varotsos, P. and Alexopoulos, K., Phys. Rev. B (1977) (published 15th January).

[4] Boyer, L. L., Harrington, J. A., Hass, M. and Rosenstock, H. B., Phys. Rev. B 11 (1975) 1665. Even if $A$ were appreciably temperature dependent, it should change the values of both $S_{m}^{+}$and $S_{m}^{-}$(given by eqs. (4) and (5)) by the same amount; thus the inequalities obtained in the present paper must be unchanged.

[5] Franklin, A. D., Statistical Thermodynamics of Point Defects in Crystals in Point defects of solids (ed. by Crawford J. and Slifkin L. M) 1972, see table XXII, pages 76-77.

[6] For instance in the case of $\mathrm{KCl}, B$ decreases linearly at high temperatures according to the relation

$B=\left(0.203-8.8 \times 10^{-6} T\right) \times 10^{12} \mathrm{erg} \mathrm{cm}^{-3}$ (see Haussuhl, S., Z. Phys. 159 (1960) 223); by considering also the values of its volume expansivity given by Srivastava, K. K. and Merchant, H. D., J. Phys. Chem. Sol. 34 (1973) 2069 we obtain for the temperature region $800 \mathrm{~K}-1000 \mathrm{~K}$ that $\mathrm{d}(B b) / \mathrm{d} T$ is negative and varies between the values

$-0.74 \times 10^{8} \sim-0.77 \times 10^{8} \mathrm{erg} \mathrm{cm}^{-3} \mathrm{grad}^{-1}$.

[7] Beniere, M., Chemla, M. and Beniere, F., J. Phys. Chem. Sol. 37 (1976) 525 ; In this paper in the case of $\mathrm{KCl}$ it is found that actually $S_{m}^{+}<S_{m}^{-}$unlike the case of $\mathrm{NaCl}$ To the best of our knowledge, from the most recent experimental works, only in this paper the inequality $S_{m}^{+}>S_{m}^{-}$(for $\mathrm{NaCl}$ ) is given.

[8] CRawford, J. H. and Slifrin, L. M., in Point defects in Solids (Plenum Press), 1972, p. 135. 